\title{
A Complementary Circular Code in the Protein Coding Genes
}

\author{
Didier G. Arquès† AND Christian J. Michel +
}

\begin{abstract}
$\dagger$ Equipe de Biologie Théorique, Université de Marne-la-Vallée, Institut Gaspard Monge, 2 rue de la butte verte, 93160 Noisy le Grand and \$Equipe de Biologie Théorique, Université de Franche-Comté, Institut Universitaire de Technologie de Belfort-Montbéliard, BP 527, 90016 Belfort, France
\end{abstract}

(Received on 16 June 1995, Accepted in revised form on 8 May 1996)

\begin{abstract}
Recently, shifted periodicities 1 modulo 3 and 2 modulo 3 have been identified in protein (coding) genes of both prokaryotes and eukaryotes with autocorrelation functions analysing eight of 64 trinucleotides (Arquès et al., 1995). This observation suggests that the trinucleotides are associated with frames in protein genes. In order to verify this hypothesis, a distribution of the 64 trinucleotides AAA,$\ldots$, TTT is studied in both gene populations by using a simple method based on the trinucleotide frequencies per frame. In protein genes, the trinucleotides can be read in three frames: the reading frame 0 established by the ATG start trinucleotide and frame 1 (resp. 2) which is the frame 0 shifted by 1 (resp. 2) nucleotide in the $5^{\prime}-3^{\prime}$ direction. Then, the occurrence frequencies of the 64 trinucleotides are computed in the three frames. By classifying each of the 64 trinucleotides in its preferential occurrence frame, i.e. the frame associated with its highest frequency, three subsets of trinucleotides can be identified in the three frames. This approach is applied in the two gene populations.

Unexpectedly, the same three subsets of trinucleotides are identified in these two gene populations: $T_{0}=X_{0} \cup\{\mathrm{AAA}, \mathrm{TTT}\}$ with $X_{0}=\{$ AAC,AAT,ACC,ATC,ATT,CAG,CTC,CTG,GAA,GAC,GAG, GAT,GCC,GGC,GGT,GTA,GTC,GTT,TAC,TTC $\}$ in frame $0, T_{1}=X_{1} \cup\{\mathrm{CCC}\}$ in frame 1 and $T_{2}=X_{2} \cup\{\mathrm{GGG}\}$ in frame 2, each subset $X_{0}, X_{1}$ and $X_{2}$ having 20 trinucleotides. Surprisingly, these three subsets have five important properties: (i) the property of maximal circular code for $X_{0}$ (resp. $\left.X_{1}, X_{2}\right)$ allowing the automatical retrieval of frame 0 (resp. 1,2) in any region of a protein gene model (formed by a series of trinucleotides of $X_{0}$ ) without using a start codon; (ii) the DNA complementarity property $C$ (e.g. $C(\mathrm{AAC})=\mathrm{GTT}): C\left(T_{0}\right)=T_{0}, C\left(T_{1}\right)=T_{2}$ and $C\left(T_{2}\right)=T_{1}$ allowing the two paired reading frames of a DNA double helix simultaneously to code for amino acids; (iii) the circular permutation property $P$ (e.g. $P($ AAC $)=$ ACA): $P\left(X_{0}\right)=X_{1}$ and $P\left(X_{1}\right)=X_{2}$ implying that the two subsets $X_{1}$ and $X_{2}$ can be deduced from $X_{0}$; (iv) the rarity property with an occurrence probability of $X_{0}$ equal to $6 \times 10^{-8}$; and $(\mathrm{v})$ the concatenation property with: a high frequency $(27.5 \%)$ of misplaced trinucleotides in the shifted frames, a maximum (13 nucleotides) length of the minimal window to automatically retrieve the frame and an occurrence of the four types of nucleotides in the three trinucleotides sites, in favour of an evolutionary code.

In the Discussion, the identified subsets $T_{0}, T_{1}$ and $T_{2}$ replaced in the three two-letter genetic alphabets purine/pyrimidine, amino/ceto and strong/weak interaction, allow us to deduce that the RNY model $(\mathrm{R}=$ purine $=\mathrm{A}$ or $\mathrm{G}, \mathrm{Y}=$ pyrimidine $=\mathrm{C}$ or $\mathrm{T}, \mathrm{N}=\mathrm{R}$ or $\mathrm{Y})$ (Eigen \& Schuster, 1978) is the closest two-letter codon model to the trinucleotides of $T_{0}$. Then, these three subsets are related to the genetic code. The trinucleotides of $T_{0}$ code for 13 amino acids: Ala, Asn, Asp, Gln, Glu, Gly, Ile, Leu, Lys, Phe, Thr, Tyr and Val. Finally, a strong correlation between the usage of the trinucleotides of $T_{0}$ in protein genes and the amino acid frequencies in proteins is observed as six among seven amino acids not coded by $T_{0}$, have as expected the lowest frequencies in proteins of both prokaryotes and eukaryotes.
\end{abstract}

(C) 1996 Academic Press Limited † Author to whom correspondence should be addressed. Present address: Institut Polytechnique de Sévernans, Rue du Château, Sévernans,
90010 Belfort, France. 


\section{Introduction}

The concept of a code without commas has been introduced by Crick et al. (1957) in order to explain how the reading of a series of nucleotides in the protein (coding) genes could code for the amino acids constituting the proteins. The two problems stressed were: why are there more codons than amino acids and how to choose the reading frame? For example, a series of nucleotides ...AGTCCGTACGA. . can be read in three frames: ...AGT,CCG,TAC,GA..., ...A,GTC,CGT,ACG,A. . and ...AG,TCC,GTA, CGA,... Crick et al. (1957) have then proposed that only 20 of 64 codons, code for the 20 amino acids. However, the determination of a set of 20 codons forming a code without commas depends on a great number of constraints. For example, the four codons with identical nucleotides AAA, CCC, GGG and TTT must be excluded from such a code. Indeed, the concatenation of AAA, for example, with itself does not allow to retrieve the frame: ...AAA,AAA,AAA, ..., . . . A,AAA,AAA,AA . . and ...AA,AAA,AAA,A... Similarly, two codons related to circular permutation, e.g. AAC and ACA (or CAA), cannot belong at the same time to such a code. Indeed, the concatenation of AAC, for example, with itself leads to the concatenation of ACA (or CAA) with itself in another frame, making the frame determination impossible. Therefore, by excluding AAA, CCC, GGG and TTT and by gathering the 60 remaining codons in 20 classes of three codons so that the three codons are deduced from each other by circular permutations, e.g. AAC, ACA and CAA, a code without commas has only one codon per class and therefore contains at most 20 codons. This codon number is identical to the amino acid number. This interesting property has naturally led to the proposal of a code without commas assigning one codon per amino acid (Crick et al., 1957). Unfortunately, the determination of a set of 20 codons forming a code without commas was not solved as there are 3.5 billion potential codes (explanation given in Section 3.4).

In contrast, Dounce (1952) has proposed earlier an evolutionary code associating several codons per amino acid. Such a flexibility can explain the variations in $\mathrm{G}+\mathrm{C}$ composition observed in the actual protein genes (Jukes \& Bhushan, 1986).

The two discoveries that the codon TTT, an "excluded" codon in the concept of code without commas, codes for phenylalanine (Nirenberg \& Matthaei, 1961) and that the protein genes are placed in the reading frame with a particular codon, namely the start codon ATG, have led to give up the concept of code without commas on the alphabet $\{\mathrm{A}, \mathrm{C}, \mathrm{G}, \mathrm{T}\}$.

For several biological reasons, in particular the interaction between mRNA and tRNA, the concept of code without commas is resumed later on the alphabet $\{\mathrm{R}, \mathrm{Y}\} \quad(\mathrm{R}=$ purine $=\mathrm{A}$ or $\mathrm{G}$, $\mathrm{Y}=$ pyrimidine $=\mathrm{C}$ or $\mathrm{T}$ ) with 2 codon models for the primitive protein genes: RRY (Crick et al., 1976) and RNY ( $\mathrm{N}=\mathrm{R}$ or $\mathrm{Y}$ ) (Eigen \& Schuster, 1978). The RNY codon model has interesting properties. Indeed, it leads to a protein gene formed by a series RNYRNY... of nucleotides so that there is one type of trinucleotide RNY in frame 0 (reading frame), one type of trinucleotide NYR in frame 1 and one type of trinucleotide YRN in frame 2 (frames 1 and 2 being the frame 0 shifted by one and two nucleotides respectively in the $5^{\prime}-3^{\prime}$ direction). RNY is self-complementary and, NYR and YRN are complementary to each other. This property allows the two paired reading frames to code simultaneously for amino acids according to a purine/pyrimidine genetic code. Furthermore, NYR is obtained by one circular permutation of RNY and YRN, by two circular permutations of RNY. This property allows NYR and YRN to be deduced from RNY. Finally, the length of the minimal sub-sequence (called window) to retrieve automatically the frame 0 in a series RNYRNY... is obviously equal to three nucleotides. Indeed, two nucleotides are insufficient as RY is both in frame 1 of RRY (RNY with $N=R$ ) and in frame 0 of RYY (RNY with $\mathrm{N}=\mathrm{Y}$ ). This property of automatically retrieving the reading frame in any region of a protein gene model (formed by a series of RNY codons) avoids having to use a start codon. The RNY model has on the reduced alphabet $\{\mathrm{R}, \mathrm{Y}\}$ some of the properties of the code identified in protein genes of prokaryotes and eukaryotes on the alphabet $\{\mathrm{A}, \mathrm{C}, \mathrm{G}, \mathrm{T}\}$.

The recent observation of shifted periodicities (1 modulo 3 and 2 modulo 3 ) in protein genes of prokaryotes and eukaryotes with autocorrelation functions analysing the eight trinucleotides obtained by specifying YRY on $\{\mathrm{A}, \mathrm{C}, \mathrm{G}, \mathrm{T}\}$ $(\mathrm{YRY}=\{\mathrm{CAC}, \mathrm{CAT}, \ldots, \mathrm{TGT}\})$, suggests that the trinucleotides have a preferential occurrence frame (Arquès et al., 1995). In order to verify this hypothesis, the occurrence frequencies of the 64 trinucleotides AAA, ..., TTT are computed in the three frames for these two gene populations. By excluding AAA, CCC, GGG and TTT and classifying each of the 60 remaining trinucleotides in the frame associated with its highest frequency, three subsets of 20 trinucleotides are identified in the three frames: $X_{0}$ 
in frame 0 and, $X_{1}$ and $X_{2}$ in the shifted frames 1 and 2 , respectively.

These three subsets $X_{0}, X_{1}$ and $X_{2}$ of 20 trinucleotides are identical in these two gene populations and have five important properties (detailed in Section 3): circular code, complementarity, circular permutation, rarity and concatenation.

(i) The circular code property: if a sequence is constructed by concatenating trinucleotides of $X_{0}$ (frame 0), like a protein gene is composed of a series of codons, and if the frame of construction is lost, e.g. situation observed when a region of a protein gene without start codon is sequenced, then the property of code assures that the constructed sequence is decomposable into a series of trinucleotides of $X_{0}$ according to a unique way. This unique decomposition can be retrieved using a window of nucleotides with a minimal length depending on $X_{0}$. In the actual protein genes, the frame 0 (reading frame) is determined by the start codon. The notion of circular added to the concept of code concerns the limit case with sequences of infinite length, i.e. without beginning and without end. We will show that $X_{0}, X_{1}$ and $X_{2}$ are maximal (20 trinucleotides) circular codes. Note: the property that $X_{0}$ is a circular code does not necessarily imply that $X_{1}$ and $X_{2}$ are also circular codes.

(ii) The complementarity property: the subset $X_{0}$ of trinucleotides is self-complementary (ten trinucleotides of $X_{0}$ are complementary to ten other trinucleotides of $X_{0}$ ) and, the subsets $X_{1}$ and $X_{2}$ of trinucleotides are complementary to each other $(20$ trinucleotides of $X_{1}$ are complementary to 20 trinucleotides of $X_{2}$ ). Therefore, the two paired reading frames may simultaneously code for amino acids, in agreement with biological results (Zull \& Smith, 1990; Konecny et al., 1993; Béland \& Allen, 1994; Konecny et al., 1995).

(iii) The circular permutation property: the two subsets $X_{1}$ and $X_{2}$ of trinucleotides can be deduced from $X_{0}$ by circular permutations of one and two nucleotides respectively (one and two circular permutations with each trinucleotide of $X_{0}$ leads to the trinucleotides of $X_{1}$ and $X_{2}$, respectively).

(iv) The rarity property: so far, no statistical analysis has been performed concerning circular codeswithtrinucleotides on the alphabet $\{\mathrm{A}, \mathrm{C}, \mathrm{G}, \mathrm{T}\}$. There are 216 circular codes with the properties mentioned above (complementary circular codes with two permutated circular codes called $\mathrm{C}^{3}$ codes) among 3.5 billion potential circular codes. Therefore, the occurrence probability of the code $X_{0}$ is equal to $6 \times 10^{-8}$. In addition, this code $X_{0}$ is observed in two independent large gene populations, the protein genes of prokaryotes (13 686 sequences) and eukaryotes (26757 sequences).

(v) The concatenation property: the circular permutation property implies that the concatenation of two trinucleotides of $X_{0}$ generates with a high probability a trinucleotide of $X_{1}$ in frame 1 and a trinucleotide of $X_{2}$ in frame 2, e.g. the concatenation CAGGAG of CAG and GAG of $X_{0}$ generates with a high probability AGG of $X_{1}$ in frame 1 and GGA of $X_{2}$ in frame 2. For $X_{0}$, this property is verified at $72.5 \%(27.5 \%$ of misplaced trinucleotides in the shifted frames), one of the lowest rate among the 216 $\mathrm{C}^{3}$ codes. Therefore, the length of the minimal window of $X_{0}$ to automatically retrieve the frame is maximum (13 nucleotides) among the $216 \mathrm{C}^{3}$ codes. Finally, the four types of nucleotides occur in the three trinucleotide sites of $X_{0}$. Therefore, the code $X_{0}$ cannot be generated by the classical methods of automatic construction of circular codes with impose constraints in the trinucleotide sites, e.g. no nucleotide A in the first trinucleotide site. These three properties (high frequency of misplaced trinucleotides, maximum length of the minimal window and occurrence of the four types of nucleotides) imply that the code $X_{0}$ has evolutionary properties (a flexible code for evolution).

In summary, the code $X_{0}$ identified in protein genes of prokaryotes and eukaryotes retrieves on the alphabet $\{A, C, G, T\}$ the properties both of the code without commas on the alphabet $\{\mathrm{R}, \mathrm{Y}\}$ (Crick et al., 1976; Eigen \& Schuster, 1978) and of the evolutionary code (Dounce, 1952).

In the Discussion, several consequences of the identified subsets $X_{0}, X_{1}$ and $X_{2}$ are studied in respect with the two-letter genetic alphabets, the genetic code, the amino acid frequencies in proteins and the complementary paired DNA sequence.

\section{Method}

The method is obvious. On the genetic alphabet $B=\{\mathrm{A}, \mathrm{C}, \mathrm{G}, \mathrm{T}\}, \quad$ there are 64 trinucleotides $w \in T=\{\mathrm{AAA}, \ldots, \mathrm{TTT}\}$. In protein genes, the trinucleotides $w^{p}$ can be read in three frames $p \in\{0,1,2\}, p=0$ : reading frame established by the start trinucleotide ATG and $p=1$ (resp. $p=2$ ): reading frame shifted by 1 (resp. 2 ) nucleotide in the $5^{\prime}-3^{\prime}$ direction. There are $64 \times 3=192$ trinucleotides $w^{p}$. The occurrence frequencies $P\left(w^{p}\right)$ are computed in two protein gene populations: prokaryotes (13686 sequences, 4708758 trinucleotides) and (nuclear) eukaryotes (26757 sequences, 11397678 trinucleotides). These large populations, obtained from the release 39 of the EMBL Nucleotide Sequence Data 
Library in the same way as described in previous studies (see e.g. Arquès \& Michel, 1990a, b for a description of data acquisition), allow to have stable frequencies. Then, each trinucleotide $w$ is classified in its frame associated with its highest frequency.

\section{Results}

3.1. IDENTIFICATION OF THREE SUBSETS OF TRINUCLEOTIDES IN THE THREE FRAMES

Table 1(a) (resp. Table 1b) gives the occurrence frequencies $P\left(w^{p}\right)$ of the 192 trinucleotides $w^{p}$ in the protein genes of prokaryotes (resp. eukaryotes). Very unexpectedly, these two tables $1(\mathrm{a}, \mathrm{b})$ show that the 64 nucleotides $w$ can easily be classified in three subsets of trinucleotides according to the frame [Table 2(a)]. The 22 trinucleotides in frame 0 form the subset $T_{0}=$ AAAA,AAC,AAT,ACC,ATC,ATT, CAG,CTC,CTG,GAA,GAC,GAG,GAT,GCC,GGC, GGT,GTA,GTC,GTT,TAC,TTC,TTT $\}$ and the 21 trinucleotides in each of the frames 1 and 2, the subsets $T_{1}$ and $T_{2}$ respectively, $T=T_{0} \cup T_{1} \cup T_{2}$ with $T_{1}$ and $T_{2}$ defined in Table 2(a). By considering the four trinucleotides with identical nucleotides, three subsets $X_{0}, X_{1}$ and $X_{2}$ can be defined from $T_{0}$, $T_{1}$ and $T_{2}: X_{0}=T_{0}-\{\mathrm{AAA}, \mathrm{TTT}\}, X_{1}=T_{1}-\{\mathrm{CCC}\}$ and $X_{2}=T_{2}-\{\mathrm{GGG}\}$. The same three subsets $T_{0}$, $T_{1}$ and $T_{2}$ are retrieved for the two populations. Among the 192 trinucleotides $w^{p}$, the few classified into two frames or misclassified [two for the prokaryotes and four for the eukaryotes, Tables 1(a,b)], have been assigned to the frame according to the properties identified with the other trinucleotides, both in prokaryotes and eukaryotes. Note: the frequencies of the three stop trinucleotides TAA, TAG and TGA in frame 0 , are obviously equal to 0 .

\subsection{COMPLEMENTARITY PROPERTY}

Recall of the DNA complementarity rule (Watson \& Crick, 1953)

(i) The DNA double helix is formed of two nucleotide sequences $s_{1}$ and $s_{2}$ connected with the nucleotide pairing (hydrogen bonds) according to the complementarity rule $C$ : the nucleotide $\mathrm{A}$ (resp. C, G, T) in $s_{1}$ pairs with the complementary nucleotide $C(\mathrm{~A})=\mathrm{T}$ (resp. $C(\mathrm{C})=\mathrm{G}, C(\mathrm{G})=\mathrm{C}$, $C(\mathrm{~T})=\mathrm{A})$ in $s_{2}$. (ii) The two nucleotide sequences $s_{1}$ and $s_{2}$ run in opposite directions (called antiparallel) in the DNA double helix: the trinucleotide $w=l_{1} l_{2} l_{3}$, $l_{1}, l_{2}, l_{3} \in\{\mathrm{A}, \mathrm{C}, \mathrm{G}, \mathrm{T}\}$, in $s_{1}$ pairs with the complementary trinucleotide $C(w)=C\left(l_{3}\right) C\left(l_{2}\right) C\left(l_{1}\right)$ in $s_{2}$.

\section{Property 1}

$C\left(T_{0}\right)=T_{0}, \quad C\left(T_{1}\right)=T_{2}$ and $\quad C\left(T_{2}\right)=T_{1} \quad$ [Table 2(b)]. $T_{0}$ is self-complementary and, $T_{1}$ and $T_{2}$ are complementary to each other.

\section{Biological consequences}

The two paired reading frames may simultaneously code for amino acids.

\subsection{CIRCULARITY PROPERTY}

Definition of the trinucleotide circular permutation

The circular permutation $P$ of the trinucleotide $w=l_{1} l_{2} l_{3}, l_{1}, l_{2}, l_{3} \in\{\mathrm{A}, \mathrm{C}, \mathrm{G}, \mathrm{T}\}$, is the permutated trinucleotide $P(w)=l_{2} l_{3} l_{1}$.

\section{Property 2}

$P\left(X_{0}\right)=X_{1}$ and $P\left(X_{1}\right)=X_{2} \quad$ [Table $\left.\quad(2 \mathrm{c})\right] . \quad X_{0}$ generates $X_{1}$ by one circular permutation and $X_{2}$ by another circular permutation.

\section{Biological consequences}

The two subsets $X_{1}$ and $X_{2}$ can be deduced from $X_{0}$.

\subsection{CIRCULAR CODE PROPERTY}

\section{Recall of a few notations}

Let $B$ be a genetic alphabet, $B_{2}=\{\mathrm{R}, \mathrm{Y}\}$ and $B_{4}=\{\mathrm{A}, \mathrm{C}, \mathrm{G}, \mathrm{T}\} . B^{*}$ denotes the words on $B$ of finite length including the empty word of length $0 . B^{+}$ denotes the words on $B$ of finite length $\geqslant 1$. Let $w_{1} w_{2}$ be the concatenation of the two words $w_{1}$ and $w_{2}$.

\section{Definition of circular code}

A subset $X$ of $B^{+}$is a circular code if for all $n, m \geqslant 1$ and $x_{1}, x_{2}, \ldots, x_{n} \in X, y_{1}, y_{2}, \ldots, y_{m} \in X$ and $p \in B^{*}$, $s \in B^{+}$, the equalities $s x_{2} x_{3} \ldots x_{n} p=y_{1} y_{2} \ldots y_{m}$ and $x_{1}=p s$ imply $n=m, p=1$ and $x_{i}=y_{i}, 1 \leqslant i \leqslant n$ [Béal, 1993; Berstel \& Perrin, 1985 and Fig. 1(a)]. In other terms, every word on $B$ "written on a circle" has at most one factorization (decomposition) over $X$.

Note: in the following, $X$ will be a set of words of three letters as a protein gene is a concatenation of trinucleotides.

\section{Basic properties and examples}

(i) If $b$ is the cardinal of the alphabet $B$, then $X$ contains at most $b^{3}$ trinucleotides [Table 2(d)]. Therefore, on $B_{2}, X$ is a subset of $\{R R R, R R Y, R Y R, R Y Y, Y R R, Y R Y, Y Y R, Y Y Y\}$ and on $B_{4}, X$ is a subset of $\{\mathrm{AAA}, \ldots, \mathrm{TTT}\}$.

(ii) There are obvious constraints so that $X$ is a circular code.

$-X$ cannot have the trinucleotides $w=111, l \in B$. For example on $B_{2}$, if $X$ contains RRR then the word 
TABLE 1(a)

Occurrence frequencies $P\left(w^{p}\right)$ of the 64 trinucleotide $w$ in each frame $p$ in the prokaryotic protein coding genes (13686 sequences, 4708758 trinucleotides)

\begin{tabular}{|c|c|c|c|c|c|}
\hline$w$ in frame $p=0$ & Frequency $(\%)$ & $w$ in frame $p=1$ & Frequency $(\%)$ & $w$ in frame $p=2$ & Frequency $(\%)$ \\
\hline AAAA & 3.38 & AAA & 2.75 & AAA & 2.44 \\
\hline AAC & 2.18 & AAC & 1.59 & AAC & 1.38 \\
\hline AAG & 1.98 & AAG & 3.21 & AAG & 0.81 \\
\hline AAT & 2.17 & AAT & 1.37 & AAT & 1.69 \\
\hline ACA & 1.22 & ACA & 1.91 & ACA & 1.11 \\
\hline $\mathrm{ACC}$ & 2.09 & $\mathrm{ACC}$ & 1.60 & $\mathrm{ACC}$ & 0.79 \\
\hline ACG & 1.30 & ACG & 2.49 & ACG & 0.68 \\
\hline ACT & 1.13 & ACT & 1.17 & ACT & 1.09 \\
\hline AGA & 0.61 & AGA & 1.59 & AGA & 2.47 \\
\hline AGC & 1.42 & AGC & 1.83 & AGC & 1.71 \\
\hline AGG & 0.31 & AGG & 2.21 & AGG & 1.45 \\
\hline AGT & 0.87 & AGT & 0.97 & AGT & 1.26 \\
\hline ATA & 0.83 & ATA & 2.15 & ATA & 0.66 \\
\hline ATC & 2.61 & ATC & 1.66 & ATC & 0.82 \\
\hline ATG & 2.38 & ATG & 2.82 & ATG & 0.41 \\
\hline ATT & 2.50 & ATT & 1.38 & ATT & 1.50 \\
\hline CAA & 1.70 & CAA & 1.47 & CAA & 2.74 \\
\hline CAC & 1.01 & CAC & 0.91 & CAC & 1.66 \\
\hline CAG & 2.21 & CAG & 1.76 & CAG & 1.16 \\
\hline CAT & 1.06 & CAT & 0.83 & CAT & 2.12 \\
\hline CCA & 0.88 & CCA & 1.81 & CCA & 1.50 \\
\hline $\mathrm{CCC}$ & 0.80 & $\mathrm{CCC}$ & 1.16 & $\mathrm{CCC}$ & 0.98 \\
\hline CCG & 1.76 & CCG & 2.74 & CCG & 1.36 \\
\hline CCT & 0.84 & CCT & 1.12 & CCT & 1.67 \\
\hline CGA & 0.41 & CGA & 1.48 & CGA & 3.50 \\
\hline CGC & 1.90 & $\mathrm{CGC}$ & 2.01 & CGC & 2.62 \\
\hline CGG & 0.79 & CGG & 2.35 & CGG & 2.77 \\
\hline CGT & 1.32 & CGT & 0.79 & CGT & 1.93 \\
\hline CTA & 0.53 & CTA & 1.08 & CTA & 1.08 \\
\hline CTC & 1.34 & CTC & 0.85 & СТC & 1.00 \\
\hline CTG & 3.44 & CTG & 1.95 & CTG & 0.94 \\
\hline СТT & 1.26 & CTT & 1.00 & CTT & 1.62 \\
\hline GAA & 3.83 & GAA & 0.78 & GAA & 2.14 \\
\hline GAC & 2.54 & GAC & 0.43 & GAC & 1.41 \\
\hline GAG & 2.40 & GAG & 0.67 & GAG & 0.63 \\
\hline GAT & 3.04 & GAT & 0.40 & GAT & 2.21 \\
\hline GCA & 1.93 & GCA & 1.79 & $G C A$ & 1.88 \\
\hline GCC & 2.93 & GCC & 1.42 & $\mathrm{GCC}$ & 1.41 \\
\hline GCG & 2.62 & GCG & 2.65 & GCG & 1.51 \\
\hline GCT & 1.89 & GCT & 1.17 & GCT & 2.48 \\
\hline GGA & 1.26 & GGA & 0.83 & GGA & 2.57 \\
\hline GGC & 3.14 & GGC & 1.02 & GGC & 2.63 \\
\hline GGG & 1.07 & GGG & 1.08 & GGG & 1.55 \\
\hline GGT & 2.17 & GGT & 0.50 & GGT & 2.06 \\
\hline GTA & 1.22 & GTA & 1.21 & GTA & 0.61 \\
\hline GTC & 1.82 & GTC & 0.92 & GTC & 0.82 \\
\hline GTG & 2.18 & $G T G$ & 1.68 & GTG & 0.47 \\
\hline GTT & 1.83 & GTT & 0.94 & GTT & 1.56 \\
\hline TAA & 0.00 & TAA & 1.33 & TAA & 2.39 \\
\hline TAC & 1.42 & TAC & 0.74 & TAC & 1.29 \\
\hline TAG & 0.00 & TAG & 1.26 & TAG & 0.60 \\
\hline TAT & 1.74 & TAT & 0.79 & TAT & 2.00 \\
\hline TCA & 0.94 & TCA & 2.18 & TCA & 1.51 \\
\hline TCC & 0.99 & TCC & 1.33 & TCC & 1.11 \\
\hline TCG & 0.95 & TCG & 2.95 & TCG & 0.86 \\
\hline TCT & 1.04 & $T C T$ & 1.19 & TCT & 1.32 \\
\hline TGA & 0.00 & TGA & 2.50 & TGA & 3.27 \\
\hline TGC & 0.57 & TGC & 2.41 & TGC & 2.41 \\
\hline TGG & 1.25 & TGG & 3.17 & $T G G$ & 1.87 \\
\hline TGT & 0.40 & TGT & 1.20 & TGT & 1.79 \\
\hline TTA & 1.55 & TTA & 1.84 & TTA & 1.00 \\
\hline TTC & 1.87 & TTC & 1.36 & TTC & 1.29 \\
\hline TTG & 1.25 & TTG & 2.90 & TTG & 0.50 \\
\hline TTT & 1.93 & TTT & 1.35 & TTT & 1.93 \\
\hline
\end{tabular}

The trinucleotides in bold have a preferential occurrence frame. The trinucleotides in italics, classified into two frames $p$ and $p^{\prime}$ $\left(\left|P\left(w^{p}\right)-P\left(w^{p^{\prime}}\right)\right| \leqslant 0.2 \%\right.$ : GCA, TCT) or misclassified $\left(\left|P\left(w^{p}\right)-P\left(w^{p^{\prime}}\right)\right|>0.2 \%\right.$ : GTG, TGG), have been assigned to the frame according to the properties identified with the other trinucleotides, both in prokaryotes and eukaryotes. 
TABLE $1(b)$

Occurrence frequencies $P\left(w^{p}\right)$ of the 64 trinucleotide $w$ in each frame $p$ in the eukaryotic protein coding genes (26757 sequences, 11397678 trinucleotides)

\begin{tabular}{|c|c|c|c|c|c|}
\hline$w$ in frame $p=0$ & Frequency $(\%)$ & $w$ in frame $p=1$ & Frequency $(\%)$ & $w$ in frame $p=2$ & Frequency $(\%)$ \\
\hline$\overline{\mathbf{A A A}}$ & 2.64 & AAA & 2.16 & AAA & 2.24 \\
\hline AAC & 2.40 & AAC & 1.33 & AAC & 1.12 \\
\hline AAG & 3.56 & $A A G$ & 2.64 & AAG & 1.05 \\
\hline AAT & 2.10 & AAT & 1.24 & AAT & 1.39 \\
\hline ACA & 1.48 & ACA & 2.79 & $\mathrm{ACA}$ & 1.28 \\
\hline ACC & 1.93 & ACC & 1.90 & ACC & 1.04 \\
\hline ACG & 0.75 & ACG & 1.62 & ACG & 0.43 \\
\hline ACT & 1.51 & ACT & 1.71 & ACT & 1.03 \\
\hline AGA & 1.23 & AGA & 2.97 & $A G A$ & 2.84 \\
\hline AGC & 1.57 & AGC & 2.28 & AGC & 1.57 \\
\hline AGG & 0.95 & AGG & 3.05 & AGG & 1.46 \\
\hline AGT & 1.10 & AGT & 1.45 & $A G T$ & 1.29 \\
\hline ATA & 0.88 & ATA & 1.51 & ATA & 0.61 \\
\hline ATC & 2.32 & ATC & 1.29 & ATC & 1.00 \\
\hline ATG & 2.31 & ATG & 3.08 & ATG & 0.57 \\
\hline ATT & 1.98 & ATT & 1.25 & ATT & 1.33 \\
\hline CAA & 1.65 & CAA & 1.55 & CAA & 3.71 \\
\hline CAC & 1.28 & CAC & 1.14 & CAC & 2.17 \\
\hline CAG & 2.66 & CAG & 2.22 & CAG & 1.82 \\
\hline CAT & 1.01 & CAT & 1.02 & CAT & 2.75 \\
\hline CCA & 1.66 & CCA & 2.91 & CCA & 2.04 \\
\hline CCC & 1.50 & CCC & 1.60 & $\mathrm{CCC}$ & 1.50 \\
\hline $\mathrm{CCG}$ & 0.73 & CCG & 1.48 & $\mathrm{CCG}$ & 1.03 \\
\hline CCT & 1.46 & CCT & 1.59 & CCT & 2.16 \\
\hline CGA & 0.53 & CGA & 0.62 & CGA & 1.94 \\
\hline CGC & 0.96 & CGC & 0.78 & CGC & 1.16 \\
\hline CGG & 0.71 & CGG & 1.10 & CGG & 1.28 \\
\hline CGT & 0.67 & CGT & 0.48 & CGT & 1.19 \\
\hline CTA & 0.73 & CTA & 1.20 & $C T A$ & 1.17 \\
\hline CTC & 1.64 & CTC & 1.44 & CTC & 1.64 \\
\hline CTG & 2.94 & CTG & 2.85 & CTG & 1.32 \\
\hline CTT & 1.27 & CTT & 1.20 & CTT & 2.13 \\
\hline GAA & 3.09 & GAA & 1.06 & GAA & 2.96 \\
\hline GAC & 2.58 & GAC & 0.63 & GAC & 1.37 \\
\hline GAG & 3.54 & GAG & 1.27 & GAG & 1.28 \\
\hline GAT & 2.68 & GAT & 0.57 & GAT & 1.70 \\
\hline GCA & 1.58 & GCA & 1.93 & $G C A$ & 1.81 \\
\hline GCC & 2.51 & GCC & 1.37 & GCC & 1.42 \\
\hline GCG & 0.83 & GCG & 1.11 & GCG & 0.80 \\
\hline GCT & 2.17 & GCT & 1.28 & $G C T$ & 1.97 \\
\hline GGA & 1.76 & GGA & 1.27 & GGA & 3.49 \\
\hline GGC & 2.08 & GGC & 0.95 & GGC & 2.08 \\
\hline GGG & 1.20 & GGG & 1.26 & GGG & 1.55 \\
\hline GGT & 1.74 & GGT & 0.61 & GGT & 1.67 \\
\hline$G T A$ & 0.78 & GTA & 0.91 & GTA & 0.73 \\
\hline GTC & 1.60 & GTC & 0.81 & GTC & 1.05 \\
\hline GTG & 2.40 & $G T G$ & 1.93 & GTG & 0.77 \\
\hline GTT & 1.55 & GTT & 0.75 & GTT & 1.35 \\
\hline TAA & 0.00 & TAA & 1.02 & TAA & 1.79 \\
\hline TAC & 1.76 & TAC & 0.68 & TAC & 1.02 \\
\hline TAG & 0.00 & TAG & 1.03 & TAG & 0.70 \\
\hline TAT & 1.34 & TAT & 0.67 & TAT & 1.40 \\
\hline TCA & 1.20 & TCA & 2.82 & TCA & 1.47 \\
\hline TCC & 1.63 & TCC & 1.85 & TCC & 1.40 \\
\hline TCG & 0.66 & TCG & 1.37 & TCG & 0.61 \\
\hline TCT & 1.56 & TCT & 1.71 & TCT & 1.42 \\
\hline TGA & 0.00 & TGA & 2.46 & TGA & 3.61 \\
\hline TGC & 1.08 & $T G C$ & 2.00 & TGC & 2.28 \\
\hline TGG & 1.21 & TGG & 3.39 & $T G G$ & 2.48 \\
\hline TGT & 0.89 & TGT & 1.36 & TGT & 2.17 \\
\hline TTA & 1.02 & TTA & 1.29 & TTA & 0.74 \\
\hline TTC & 2.20 & TTC & 1.36 & TTC & 1.34 \\
\hline TTG & 1.50 & TTG & 2.69 & TTG & 0.61 \\
\hline TTT & 1.75 & TTT & 1.14 & TTT & 1.70 \\
\hline
\end{tabular}

The trinucleotides in bold have a preferential occurrence frame. The trinucleotides in italics, classified into two frames $p$ and $p^{\prime}$ $\left(\left|P\left(w^{p}\right)-P\left(w^{p^{\prime}}\right)\right| \leqslant 0.2 \%\right.$ : AGA, AGT, CTA, GCA, GCT, GTA) or misclassified $\left(\left|P\left(w^{p}\right)-\left(w^{p^{\prime}}\right)\right|>0.2 \%\right.$ : AAG, GTG, TGC, TGG), have been assigned to the frame according to the properties identified with the other trinucleotides, both in prokaryotes and eukaryotes. 
...RRRRRRR. . has three factorizations over $X$ : ...RRR,RRR,..., ...R,RRR,RR. . and . . RR,RRR,R. . Therefore, $X$ will be a subset of $B_{2}^{\prime}=\{R R Y, R Y R, R Y Y, Y R R, Y R Y, Y Y R\}$. Similarly on $B_{4}, X$ will be a subset of $B_{4}^{\prime}=\{\mathrm{AAA}, \ldots$, TTT $\}-\{$ AAA,CCC,GGG,TTT $\}$. The cardinal of $B^{\prime}$ is $b^{3}-b$, i.e. six for $B_{2}^{\prime}$ and 60 for $B_{4}^{\prime}$.

$-X$ cannot have two trinucleotides at the same time deduced from each other by circular permutation. For example on $B_{2}$, if $X$ contains RRY and RYR (RYR is one circular permutation of RRY) then the word . . RRYRRYRRY. . . has two factorizations over $X$ : . . RRY,RRY,RRY, . . and . . R,RYR,RYR,RY. . Therefore, by gathering the six trinucleotides of $B_{2}^{\prime}$ in two classes of three codons so that the three codons are deduced from each other by circular permutations \{RRY,RYR,YRR $\}$ and $\{\mathrm{RYY}, \mathrm{YYR}, \mathrm{YRY}\}, X$ has at most one trinucleotide in each class. The number of classes invariant by circular permutation is $\operatorname{Card}\left(B^{\prime}\right) / 3=\left(b^{3}-b\right) / 3$, i.e. two on $B_{2}$ and 20 on $B_{4}$ [Table 2(d)]. Therefore, $X$ contains at most two trinucleotides and $3^{2}=9$ sets $X$ are potential (maximal) circular codes. The number of potential (maximal) circular codes is $3^{\left(b^{3}-b\right) / 3}$, i.e. $3^{2}=9$ on $B_{2}$ and $3^{20}=3486784401$ on $B_{4}$ [Table 2(d)]. For example, $X_{a}=\{\mathrm{RRY}, \mathrm{RYY}\}$ is a circular code. Indeed, the concatenation of two trinucleotides of $X_{\mathrm{a}}$, . . RRYRRY . . . . . . RRYRYY . . . . . RYYRRY ... and ... RYYRYY ... leads to only one factorization over $X_{a}$ as the eventual decomposition in frame 1 always has a $\mathrm{R}$ in the third position but no trinucleotide of $X_{a}$ ends with $\mathrm{R}$ and as the eventual decomposition in frame 2 always has a $Y$ in the first position but no trinucleotide of $X_{a}$ begins with Y. $X_{a}$ is a maximal (two trinucleotides) circular code and corresponds to the RNY model (Eigen \& Schuster, 1978). $X_{a}$ is self-complementary (complementary circular code), i.e. $C\left(X_{a}\right)=X_{a}$, as RRY and RYY are complementary. Any subset of $X_{a}$ is also a circular code but not maximal. For example, the subset RRY is a circular code and corresponds to the RRY model (Crick et al., 1976). The two subsets

TABLE 2(a)

List of the trinucleotides per frame in lexicographical order deduced from the Tables $1(a, b)$

$T_{0}$ AAA AAC AAT ACC ATC ATT CAG CTC CTG GAA GAC GAG GAT GCC GGC GGT GTA GTC GTT TAC TTC TTT

$T_{1}$ AAG ACA ACG ACT AGC AGG ATA ATG CCA CCC CCG GCG GTG TAG TCA TCC TCG TCT TGC TTA TTG

$T_{2}$ AGA AGT CAA CAC CAT CCT CGA CGC CGG CGT CTA CTT GCA GCT GGA GGG TAA TAT TGA TGG TGT

Three subsets of trinucleotides can be identified: $T_{0}=X_{0} \cup\{$ AAA,TTT $\}$ in frame $p=0, T_{1}=X_{1} \cup\{\mathrm{CCC}\}$ in frame $p=1$ and $T_{2}=X_{2} \cup\{\mathrm{GGG}\}$ in frame $p=2$.

TABLE 2(b)

Complementarity property with the three subsets $T_{0}, T_{1}$ and $T_{2}$ of trinucleotides identified in Table 2(a)

$T_{0}$ AAA AAC AAT ACC ATC CAG CTC GAA GAC GCC GTA

$T_{0}$ TTT GTT ATT GGT GAT CTG GAG TTC GTC GGC TAC

$T_{1}$ AAG ACA ACG ACT AGC AGG ATA ATG CCA CCC CCG GCG GTG TAG TCA TCC TCG TCT TGC TTA TTG

$T_{2}$ CTT TGT CGT AGT GCT CCT TAT CAT TGG GGG CGG CGC CAC CTA TGA GGA CGA AGA GCA TAA CAA

TABLE 2(c)

Circularity property with the three subsets $X_{0}, X_{1}$ and $X_{2}$ of trinucleotides identified in Table 2(a)

$X_{0}$ AAC AAT ACC ATC ATT CAG CTC CTG GAA GAC GAG GAT GCC GGC GGT GTA GTC GTT TAC TTC

$X_{1}$ ACA ATA CCA TCA TTA AGC TCC TGC AAG ACG AGG ATG CCG GCG GTG TAG TCG TTG ACT ACT

$X_{2}$ CAA TAA CAC CAT TAT GCA CCT GCT AGA CGA GGA TGA CGC CGG TGG AGT CGT TGT CTA CTT

TABLE 2(d)

Circular code statistics on the alphabets $\{R, Y\}$ and $\{A, C, G, T\}$

\begin{tabular}{lll}
\hline Alphabet & $\{\mathrm{R}, \mathrm{Y}\}$ & $\{\mathrm{A}, \mathrm{C}, \mathrm{G}, \mathrm{T}\}$ \\
\hline Cardinal b of the alphabet & 2 & 4 \\
Cardinal b $\mathrm{b}^{3}$ of the trinucleotides & $2^{3}=8$ & $4^{3}=64$ \\
Number $\left(\mathrm{b}^{3}-\mathrm{b}\right) / 3$ of classes invariant & $(8-2) / 3=2$ & $(64-4) / 3=20$ \\
$\quad$ by circular permutation & $3^{2}=9$ & $3^{20}=3486784401$ \\
Number $\left.3^{\left(\mathrm{b}^{3}\right.}-\mathrm{b}\right) / 3$ of potential (maximal) circular codes & 8 & 12964440 \\
Number of (maximal) circular codes & 0.89 & $3.7 \times 10^{-3}$ \\
Probability of (maximal) circular codes & 2 & 528 \\
Number of (maximal) complementary circular codes & 0.22 & $1.5 \times 10^{-7}$ \\
Probability of (maximal) complementary circular codes & 2 & 216 \\
Number of (maximal) complementary circular codes & & $6.2 \times 10^{-8}$ \\
$\quad$ with 2 permutated circular codes $\left(C^{3}\right.$ codes) & 0.22 & \\
Probability of C $\mathrm{C}^{3}$ codes & &
\end{tabular}


(a)

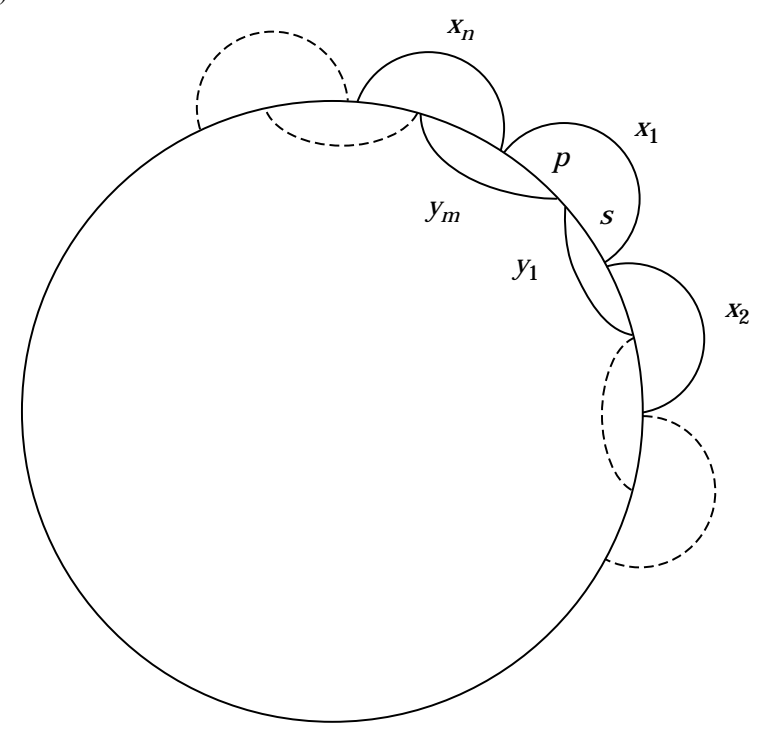

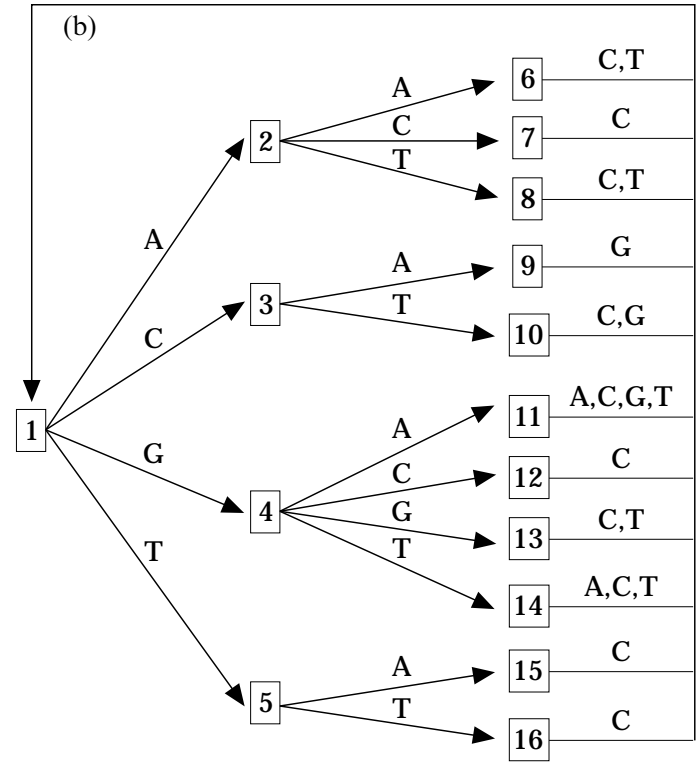

Frame $0 \quad$ Frame $1 \quad$ Frame 2

Fig. 1. (a) A representation of the definition of a circular code. (b) Flower automaton $F\left(X_{0}\right)$ associated with the circular code $X_{0}$.

$X_{b}=P\left(X_{a}\right)=\{\mathrm{RYR}, \mathrm{YYR}\} \quad$ and $\quad X_{c}=P\left(X_{b}\right)=$ $\{$ YRR, YRY $\}$ obtained by circular permutations of $X_{a}$ are also maximal circular codes (identical proof). $X_{b}$ and $X_{c}$ are complementary to each other, i.e. $C\left(X_{b}\right)=X_{c}$ and $C\left(X_{c}\right)=X_{b}$, as RYR (resp. YYR) and YRY (resp. YRR) are complementary. The previous results remain unchanged by substituting $\mathrm{R}$ by $\mathrm{Y}$ and reciprocally. Therefore, $X_{d}=\{\mathrm{YRR}, \mathrm{YYR}\}$ is a maximal complementary circular code $\left(C\left(X_{d}\right)=X_{d}\right)$ whose two subsets $X_{e}=P\left(X_{d}\right)=\{\mathrm{RRY}, \mathrm{YRY}\} \quad$ and $\quad X_{f}=P\left(X_{e}\right)=$ $\{\mathrm{RYR}, \mathrm{RYY}\}$ obtained by circular permutations of $X_{d}$ are also maximal circular codes and complementary to each other $\left(C\left(X_{e}\right)=X_{f}\right.$ and $\left.C\left(X_{f}\right)=X_{e}\right)$. The three remaining sets $X$ are $X_{g}=\{\mathrm{RYY}, \mathrm{YRR}\}$ and $X_{h}=P\left(X_{g}\right)=C\left(X_{g}\right)=\{\mathrm{RRY}, \mathrm{YYR}\}$ which are circular codes and $X_{i}=P\left(X_{h}\right)=\{\mathrm{RYR}, \mathrm{YRY}\}$ which is not a circular code as the word ...RYRYRYRYR $\ldots$ has two factorizations over $X_{i}: \ldots$ RYR,YRY,RYR, . . and ...R,YRY,RYR,YR. . On $B_{2}$ eight among nine sets $X$ are circular codes and two sets $X_{a}=\{\mathrm{RRY}, \mathrm{RYY}\}=\mathrm{RNY} \quad$ and $X_{d}=\{\mathrm{YRR}, \mathrm{YYR}\}=\mathrm{YNR}$ are complementary circular codes with two permutated circular codes (called $\mathrm{C}^{3}$ codes) [Table 2(d)].

The study of circular codes on $B_{4}$ is obviously more complex. For example, the search of a unique factorization needs the introduction of some classical definitions and results in coding theory, e.g. the flower automaton (Béal, 1993; Berstel \& Perrin, 1985). The results obtained on $\{\mathrm{A}, \mathrm{C}, \mathrm{G}, \mathrm{T}\}$ are new and very significant, from a biological as well as a computational point of view.

\section{Property 3}

The subset $X_{0}$ is a maximal (20 trinucleotides) circular code. The subsets $X_{1}$ and $X_{2}$ are also maximal circular codes.

Proof: (i) Proof of the maximum cardinal of a circular code:

The 60 words of $B_{4}^{\prime}=\{\mathrm{AAA}, \ldots, \mathrm{TTT}\}-$ \{AAA,CCC,GGG,TTT\} are gathered in 20 classes invariant by circular permutation. A circular code with words of three letters on $B_{4}$ has at most one word in each class and then contains at most 20 words.

(ii) Proof that $X_{0}$ is a circular code:

As on $B_{4}$ there are $3^{20}=3486784401$ potential circular codes, the use of some theorems in coding theory are necessary to the development of algorithms for determining automatically the circular codes. We give these basic theorems, the algorithms written in Pascal will be described elsewhere.

Definition 1: A deterministic finite state automaton $A$ is said local if an integer $n$ exists so that any two paths in $A$ of the same length $n$ and of the same associated word, have the same terminal state.

Lemma 1: If $A$ is a strongly connected automaton, the two following properties are equivalent: $A$ is local and $A$ does not contain two cycles with the same labelled word (Béal, 1993).

Definition 2: The flower automaton $F(X)$ associated with a subset $X$ of $B^{+}$has a particular state [labelled 
1 in Fig. 1(b)] and cycles issued from this state 1 and labelled by words of $X$.

Lemma 2: A finite subset $X$ of $B^{+}$is a finite circular code if and only if the flower automaton $F(X)$ is a local automaton (Béal, 1993).

Fig. 1(b) gives the flower automaton $F\left(X_{0}\right)$ associated with $X_{0}$. To prove that " $X_{0}$ is a circular code" is equivalent to prove that " $F\left(X_{0}\right)$ is local", i.e. $F\left(X_{0}\right)$ does not contain two cycles labelling the same word. This proof can be done by hand (rather tedious and not explained here) or by algorithm. The algorithm developed identifies automatically all possible subsets $X$ of $B^{+}$verifying the proof of circular code and allows statistics with circular codes (Section 3.6).

Properties 1, 2 and 3 imply that $X_{0}$ is a complementary circular code with two permutated circular codes (called $\mathrm{C}^{3}$ code).

\subsection{AUTOMATIC FRAME DETERMINATION PROPERTY}

The automatic frame determination property is a consequence of the circular code property. If a word is constructed by concatenating words of $X_{0}$ and if the frame of construction is lost, then the property of the code assures that it can be retrieved in a unique way. Such a decomposition is called the reading frame of the word according to the code $X_{0}$.

The associated flower automaton $F\left(X_{0}\right)$ has several properties as all words of $X_{0}$ have a length of three letters [Fig. 1(b)]. Therefore, the states can be associated with frames, state 1 with frame 0 , states $2-5$ with frame 1 and states $6-16$ with frame 2 . If any letter of a word, obtained by a concatenation of words of $X_{0}$, can be associated with a unique state of the automaton $F\left(X_{0}\right)$, then a frame can be deduced for this letter because the associated unique state of $F\left(X_{0}\right)$ is related to a given frame. As a consequence, the word can be decomposed in words of $X_{0}$ : its reading frame according to $X_{0}$ is then retrieved. The problem consists then in identifying such a unique state for a letter of the word. Such a unicity is not obvious. For example, the factor $w^{\prime}=$ AGGTAATTACCA of length 12 can be attributed to two reading frames according to $X_{0}$ : frame 1 (initial state 3 or 4 of $w^{\prime}$ in $F\left(X_{0}\right)$ ) or frame 2 (initial state 14 of $w^{\prime}$ in $F\left(X_{0}\right)$ ) [Fig. 2(a)].

In the case of a local automaton $A$, Definition 1 asserts that there exists $n$ so that for a word of length $\geqslant n$, all paths associated with this word have the same terminal state and thus, the reading frame of the word according to $X_{0}$ can be determined. For $A=F\left(X_{0}\right), n$ is equal to 13 and $F\left(X_{0}\right)$ is called a 13-local automaton. In other words, the size of the minimal window to retrieve always the frame is 13 letters with (a)

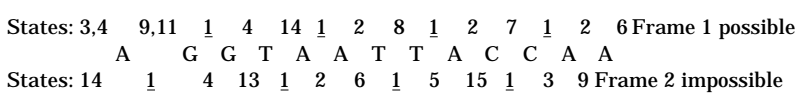

(b)

\begin{tabular}{|c|c|c|}
\hline \multicolumn{3}{|c|}{ 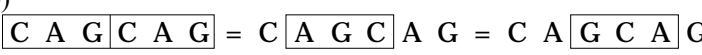 } \\
\hline Frame 0 & $\begin{array}{c}\text { Frame } 1 \\
\text { Expected } \\
\text { trinucleotide }\end{array}$ & $\begin{array}{c}\text { Frame } 2 \\
\text { Expected } \\
\text { trinucleotide }\end{array}$ \\
\hline \begin{tabular}{|l|l|l|}
$C A$ & $G A$ \\
\end{tabular} & $A G G A$ & $=A G A G$ \\
\hline Frame 0 & $\begin{array}{c}\text { Frame } 1 \\
\text { Expected } \\
\text { trinucleotide }\end{array}$ & $\begin{array}{c}\text { Frame } 2 \\
\text { Expected } \\
\text { trinucleotide }\end{array}$ \\
\hline \begin{tabular}{|lllll}
$G$ & $G$ & $T$ & $A$ & $C$ \\
\end{tabular} & G T A & $\mathrm{G} T \mathrm{~T} A \mathrm{C}$ \\
\hline Frame 0 & $\begin{array}{c}\text { Frame } 0 \\
\text { Unexpected }\end{array}$ & $\begin{array}{c}\text { Frame } 0 \\
\text { Unexpected }\end{array}$ \\
\hline
\end{tabular}

FIG. 2. (a) An example of the automatic frame determination of a word of length $\geqslant 13$ with the flower automaton $F\left(X_{0}\right)$ [Fig. 1(b)]. (b) Examples of three concatenations of two trinucleotides of the $\mathrm{C}^{3}$ code $X_{0}$ generating expected and unexpected trinucleotides in the shifted frames 1 and 2 .

$X_{0}$. For example, the first letter of the word $w=w^{\prime} A$ of length 13 is attributed to the unique frame, the frame 1 , as there is no edge labelled A leaving the state 9 of $F\left(X_{0}\right)$. Then, the unique decomposition of $w$ according to $X_{0}$ is AG,GTA,ATT,ACC,AA.

The length $n$ of the minimal window to retrieve automatically the reading frame of a word according to $X_{0}$ can be determined by algorithm testing all possible paths in the automaton (Section 3.7).

\section{Biological consequences}

The code $X_{0}$ can retrieve automatically the frame 0 in any region of a protein gene model (formed by a series of trinucleotides of $X_{0}$ ) without using a start codon.

\subsection{RARITY PROPERTY}

Statistics concerning circular codes with trinucleotides on the 4-letter alphabet $\{\mathrm{A}, \mathrm{C}, \mathrm{G}, \mathrm{T}\}$ allow to determine the occurrence probability of the code $X_{0}$.

There are $3^{20}=3486784401$ potential circular codes [Section 3.4 and Table 2(d)].

The number of circular codes computed with an algorithm verifying the definition of circular code among the $3^{20}$ circular codes, is 12964440 .

The computed number of circular codes having the complementarity property (complementary circular codes), is 528 .

The computed number of complementary circular codes with two permutated circular codes $\left(\mathrm{C}^{3}\right.$ codes $)$, is 216. Therefore, the probability to have a $\mathrm{C}^{3}$ code, e.g. 
$X_{0}$, is $216 / 3^{20}=6.2 \times 10^{-8}$. This very low probability explains the difficulty in determining such $\mathrm{C}^{3}$ codes by hand or by the classical construction methods since the proposition of a code without commas by Crick et al. in 1957.

Table 2(d) summarizes the circular code statistics on the alphabets $\{\mathrm{R}, \mathrm{Y}\}$ and $\{\mathrm{A}, \mathrm{C}, \mathrm{G}, \mathrm{T}\}$.

\section{Biological consequences}

The probability to observe the code $X_{0}$ in protein genes is very low and non-random.

\subsection{CONCATENATION PROPERTY}

The $\mathrm{C}^{3}$ code $X_{0}$ identified in protein genes has some concatenation properties (flexibility) compared with the other $\mathrm{C}^{3}$ codes:

(i) The largest window length. The lengths of minimal windows to retrieve the frame in the $216 \mathrm{C}^{3}$ codes are 5, 7, 9 and 13 (13 for $X_{0}$, Section 3.5).

(ii) A circularity property with a high frequency of misplaced trinucleotides in the shifted frames. The concatenation of two identical trinucleotides (process called duplication in biology) of $X_{0}$ (e.g. CAG $\in X_{0}$ ) leads obviously to the expected trinucleotides in the shifted frames [first example in Fig. 2(b)]. However, the probability of this type of concatenation is too low $(1 / 20)$ to explain the circularity property. The concatenation of two different trinucleotides of $X_{0}$ may lead to the expected trinucleotides in the shifted frames (e.g. $\mathrm{CAG} \in X_{0}$ and $\mathrm{GAG} \in X_{0}$ generate AGG $\in X_{1}$ and $\left.\mathrm{GGA} \in X_{2}\right)$ or not $\left(\mathrm{GGT} \in X_{0}\right.$ and ACC $\in X_{0}$ generate GTA $\notin X_{1}$ and TAC $\notin X_{2}$ ) [second and third examples in Fig. 2(b)]. Figure 3 shows the repartition function of the $216 \mathrm{C}^{3}$ codes according to the frequency of misplaced trinucleotides in frame 1 or 2 (the two shifted frames having the same frequency of misplaced trinucleotides by the complementarity property) generated by the concatenation of trinucleotides of a given $\mathrm{C}^{3}$ code. This frequency is between $6.5 \%$ and $31 \%$, and equal to $27.5 \%$ for $X_{0}$.

(iii) An occurrence of the four types of nucleotides in the three trinucleotide sites.

\section{Biological consequences}

The code $X_{0}$ has evolutionary properties.

As the $\mathrm{C}^{3}$ code $X_{0}$ leads to $72.5 \%(100-27.5)$ well-placed trinucleotides in the shifted frames (Fig. 3), the protein genes can be simulated with an independent mixing of the 20 trinucleotides of $X_{0}$ with equiprobability. Indeed, such a simulation retrieves the two other subsets $X_{1}$ and $X_{2}$ of trinucleotides in the frames 1 and 2 respectively (data not shown).

\section{Discussion}

\subsection{CONSEQUENCES ON THE TWO-LETTER ALPHABETS}

The three subsets $T_{0}, T_{1}$ and $T_{2}$ classify the $\mathrm{A} / \mathrm{C} / \mathrm{G} / \mathrm{T}$ trinucleotides according to their preferential occurrence frame. Therefore, a preferential occurrence frame for the eight $\mathrm{R} / \mathrm{Y}$ trinucleotides can be deduced from the frames of the $64 \mathrm{~A} / \mathrm{C} / \mathrm{G} / \mathrm{T}$ trinucleotides by considering for each $\mathrm{R} / \mathrm{Y}$ trinucleotide, the average frame of the eight frames associated with the eight $\mathrm{A} / \mathrm{C} / \mathrm{G} / \mathrm{T}$ specified trinucleotides. Table 3(a) shows that the subset $Y_{0}=\{\mathrm{RRY}, \mathrm{RYY}\}=\mathrm{RNY}$ occurs preferentially in frame 0 , the subset $Y_{1}=\{\mathrm{RYR}, \mathrm{YYR}\}$, in frame 1 , and the subset $Y_{2}=\{Y R R, Y R Y\}$, in frame 2. RRY and RYY have the same number (6) of $\mathrm{A} / \mathrm{C} / \mathrm{G} / \mathrm{T}$ trinucleotides in frame $0 . Y_{0}$ contains a few $\mathrm{A} / \mathrm{C} / \mathrm{G} / \mathrm{T}$

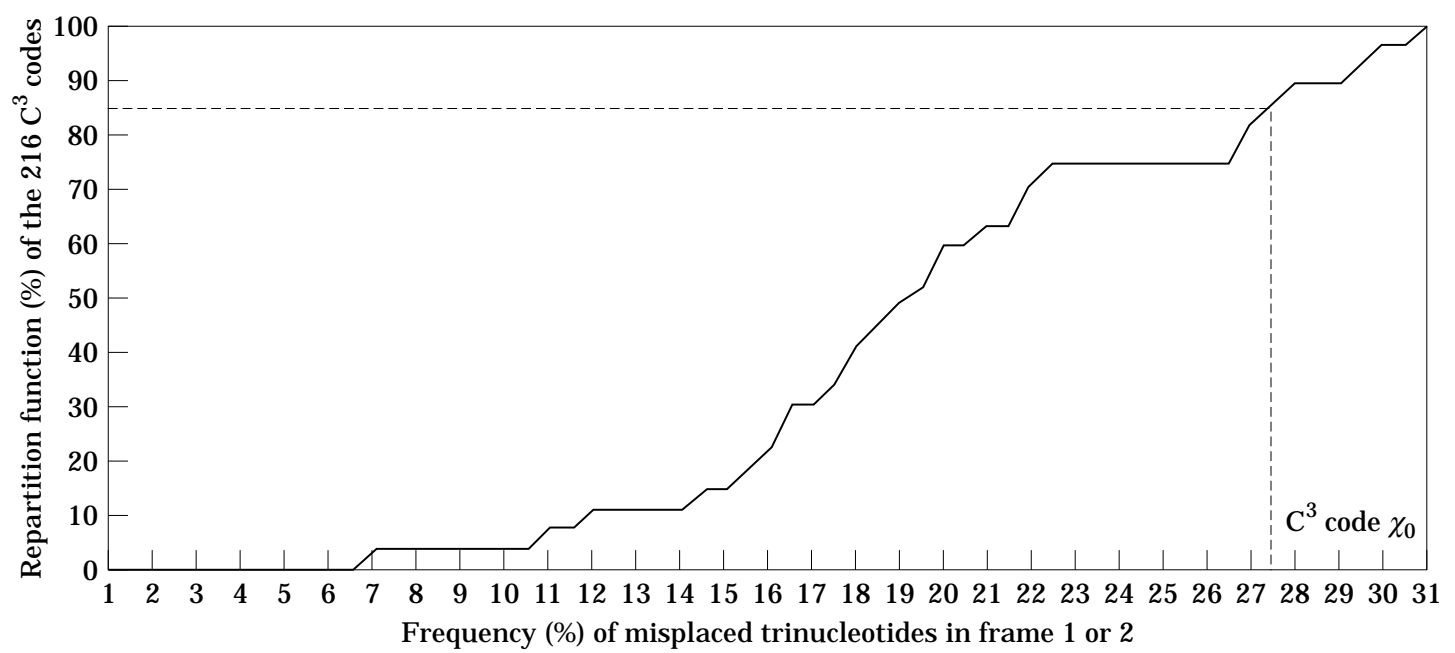

FIG. 3. Repartition function of the $216 \mathrm{C}^{3}$ codes according to the frequency of misplaced trinucleotides in frame 1 or 2 generated by the concatenation of trinucleotides of a given $\mathrm{C}^{3}$ code. The frequency of misplaced trinucleotides for the $\mathrm{C}^{3}$ code $X_{0}$ is equal to $27.5 \%$. 
trinucleotides in frames $1\left(\mathrm{ACT}^{1}, \mathrm{AGC}^{1}\right)$ and 2 $\left(\mathrm{AGT}^{2}, \mathrm{GCT}^{2}\right)$ and $Y_{1}$ and $Y_{2}$, a few $\mathrm{A} / \mathrm{C} / \mathrm{G} / \mathrm{T}$ trinucleotides in frame $0\left(\mathrm{CAG}^{0}, \mathrm{CTG}^{0}, \mathrm{GTA}^{0}\right.$, TAC $^{0}$ ). The subset $Y_{0}$ is a $\mathrm{C}^{3}$ code on $\{\mathrm{R}, \mathrm{Y}\}$ (Section 3.4) and corresponds to the RNY codon model (Eigen \& Schuster, 1978). There is no preferential frame for RRR and YYY.

These results also explain different previous works analysing the three frames simultaneously (average frame) in protein genes with autocorrelation functions on the alphabet $\{\mathrm{R}, \mathrm{Y}\}$, in particular: (i) the periodicity 0 modulo 3 with the autocorrelation function YRY $(\mathrm{N})_{i}$ YRY (Arquès \& Michel, 1987, 1994) as the trinucleotides YRY occurring preferentially in frame 2 generate a number multiple of three bases between them; and (ii) the absence of the periodicity 0 modulo 3 with the autocorrelation function $\mathrm{RRR}(\mathrm{N}){ }_{i} \mathrm{RRR}$ (Arquès \& Michel,

TABLE 3(a)

The eight $R / Y$ trinucleotides $(R=$ purine $=A$ or $G, Y=$ pyrimidine $=C$ or $T)$ are associated with the $64 A / C / G / T$ trinucleotides by considering their frame $\left(T_{0}, T_{1}, T_{2}\right)$

\begin{tabular}{|c|c|c|c|c|c|c|c|}
\hline RRR & RRY & RYR & RYY & YRR & YRY & YYR & YYY \\
\hline $\mathrm{AAA}^{0}$ & $\mathrm{AAC}^{0}$ & $\mathrm{ACA}^{1}$ & $\mathrm{ACC}^{0}$ & $\mathrm{CAA}^{2}$ & $\mathrm{CAC}^{2}$ & $\mathrm{CCA}^{1}$ & $\mathrm{CCC}^{1}$ \\
\hline $\mathrm{AAG}^{1}$ & $\mathrm{AAT}^{0}$ & $\mathrm{ACG}^{1}$ & $\mathrm{ACT}^{1}$ & $\mathrm{CAG}^{0}$ & $\mathrm{CAT}^{2}$ & $\mathrm{CCG}^{1}$ & $\mathrm{CCT}^{2}$ \\
\hline $\mathrm{AGA}^{2}$ & $\mathrm{AGC}^{1}$ & $\mathrm{ATA}^{1}$ & $\mathrm{ATC}^{0}$ & $\mathrm{CGA}^{2}$ & $\mathrm{CGC}^{2}$ & $\mathrm{CTA}^{2}$ & $\mathrm{CTC}^{0}$ \\
\hline $\mathrm{AGG}^{1}$ & $\mathrm{AGT}^{2}$ & $\mathrm{ATG}^{1}$ & $\mathrm{ATT}^{0}$ & $\mathrm{CGG}^{2}$ & $\mathrm{CGT}^{2}$ & $\mathrm{CTG}^{0}$ & $\mathrm{CTT}^{2}$ \\
\hline $\mathrm{GAA}^{0}$ & $\mathrm{GAC}^{0}$ & $\mathrm{GCA}^{2}$ & $\mathrm{GCC}^{0}$ & $\mathrm{TAA}^{2}$ & $\mathrm{TAC}^{0}$ & $\mathrm{TCA}^{1}$ & $\mathrm{TCC}^{1}$ \\
\hline $\mathrm{GAG}^{0}$ & $\mathrm{GAT}^{0}$ & $\mathrm{GCG}^{1}$ & $\mathrm{GCT}^{2}$ & $\mathrm{TAG}^{1}$ & TAT $^{2}$ & $\mathrm{TCG}^{1}$ & $\mathrm{TCT}^{1}$ \\
\hline $\mathrm{GGA}^{2}$ & $\mathrm{GGC}^{0}$ & $\mathrm{GTA}^{0}$ & $\mathrm{GTC}^{0}$ & $\mathrm{TGA}^{2}$ & $\mathrm{TGC}^{1}$ & $\mathrm{TTA}^{1}$ & $\mathrm{TTC}^{0}$ \\
\hline $\mathrm{GGG}^{2}$ & $\mathrm{GGT}^{0}$ & $\mathrm{GTG}^{1}$ & $\mathrm{GTT}^{0}$ & $\mathrm{TGG}^{2}$ & $\mathrm{TGT}^{2}$ & $\mathrm{TTG}^{1}$ & $\mathrm{TTT}^{0}$ \\
\hline $0,1,2$ & 0 & 1 & 0 & 2 & 2 & 1 & $0,1,2$ \\
\hline
\end{tabular}

The last row gives the preferential occurrence frame for the $\mathrm{R} / \mathrm{Y}$ trinucleotides, e.g. RRR is in the three frames (three $\mathrm{A} / \mathrm{C} / \mathrm{G} / \mathrm{T}$ trinucleotides in frame 0 , two in frame 1 , three in frame 2), $\mathrm{YRY}$ is in frame 2 (one $\mathrm{A} / \mathrm{C} / \mathrm{G} / \mathrm{T}$ trinucleotide in frame 0 , one in frame 1 , six in frame 2).

TABLE 3(b)

The eight $K / M$ trinucleotides $(K=$ ceto $=G$ or $T, M=$ amino $=A$ or $C)$ are associated with the $64 A / C / G / T$ trinucleotides by considering their

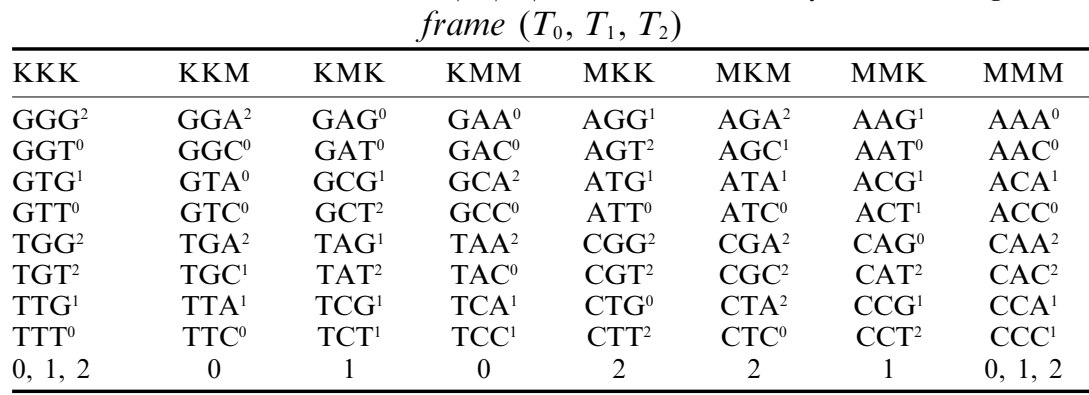

The last row gives the preferential occurrence frame for the $\mathrm{K} / \mathrm{M}$ trinucleotides.

TABLE 3(c)

The eight $S / W$ trinucleotides $(S=$ strong interaction $=C$ or $G, W=$ weak interaction $=A$ or $T)$ are associated with the $64 A / C / G / T$ trinucleotides by considering their frame $\left(T_{0}, T_{1}, T_{2}\right)$

\begin{tabular}{llllllll}
\hline SSS & SSW & SWS & SWW & WSS & WSW & WWS & WWW \\
\hline CCC $^{1}$ & CCA $^{1}$ & CAC $^{2}$ & CAA $^{2}$ & ACC & ACA $^{1}$ & AAC $^{0}$ & AAA $^{0}$ \\
CCG $^{1}$ & CCT $^{2}$ & CAG $^{0}$ & CAT $^{2}$ & ACG & ACT & AAG $^{1}$ & AAT $^{0}$ \\
CGC $^{2}$ & CGA $^{2}$ & CTC $^{0}$ & CTA $^{2}$ & AGC & AGA $^{2}$ & ATC $^{0}$ & ATA $^{1}$ \\
CGG $^{2}$ & CGT $^{2}$ & CTG $^{0}$ & CTT $^{2}$ & AGG & AGT $^{2}$ & ATG $^{1}$ & ATT $^{0}$ \\
GCC $^{0}$ & GCA $^{2}$ & GAC $^{0}$ & GAA $^{0}$ & TCC $^{1}$ & TCA $^{1}$ & TAC $^{0}$ & TAA $^{2}$ \\
GCG $^{1}$ & GCT $^{2}$ & GAG $^{0}$ & GAT $^{0}$ & TCG $^{1}$ & TCT $^{1}$ & TAG $^{1}$ & TAT $^{2}$ \\
GGC $^{0}$ & GGA $^{2}$ & GTC $^{0}$ & GTA $^{0}$ & TGC $^{1}$ & TGA $^{2}$ & TTC $^{0}$ & TTA $^{1}$ \\
GGG $^{2}$ & GGT $^{0}$ & GTG $^{1}$ & GTT $^{0}$ & TGG & TGT & TTG $^{1}$ & TTT $^{0}$ \\
$0,1,2$ & 2 & 0 & 0,2 & 1 & 1,2 & 0,1 & $0,1,2$ \\
\hline
\end{tabular}

The last row gives the preferential occurrence frame for the $\mathrm{S} / \mathrm{W}$ trinucleotides. 
1993) as RRR does not occur in a preferential frame.

This approach can be applied to the alphabets $\{\mathrm{K}, \mathrm{M}\}(\mathrm{K}=$ ceto $=\mathrm{G}$ or $\mathrm{T}, \mathrm{M}=\operatorname{amino}=\mathrm{A}$ or $\mathrm{C})$ and $\{\mathrm{S}, \mathrm{W}\} \quad(\mathrm{S}=$ strong interaction $=\mathrm{C}$ or $\mathrm{G}$, $\mathrm{W}=$ weak interaction $=\mathrm{A}$ or $\mathrm{T})$. On the alphabet $\{\mathrm{K}, \mathrm{M}\}$, Table 3(b) shows that the subset $Z_{0}=\{\mathrm{KKM}, \mathrm{KMM}\}$ occurs preferentially in frame 0 , the subset $Z_{1}=\{\mathrm{KMK}, \mathrm{MMK}\}$, in frame 1, and the subset $Z_{2}=\{\mathrm{MKK}, \mathrm{MKM}\}$, in frame 2. On the alphabet $\{\mathrm{S}, \mathrm{W}\}$, Table 3(c) shows that SWS occurs preferentially in frame 0 , WSS, in frame 1, and SSW, in frame 2. The subset $Z_{0}=\{\mathrm{KKM}, \mathrm{KMM}\}$ (resp. SWS) is a maximal (resp. not maximal) circular code with two permutated circular codes (but no complementary).

The subset $Y_{0}$ (resp. $Z_{0}$, SWS) in frame 0 contains 12 (resp. 8, 6) $\mathrm{A} / \mathrm{C} / \mathrm{G} / \mathrm{T}$ trinucleotides in frame 0 . Therefore, the alphabet $\{R, Y\}$ is the closest two-letter alphabet to the alphabet $\{\mathrm{A}, \mathrm{C}, \mathrm{G}, \mathrm{T}\}$ and the subset $Y_{0}=\mathrm{RNY}$, the closest two-letter codon model to the trinucleotides of $T_{0}$.

\subsection{CONSEQUENCES ON THE GENETIC CODE}

The codon subset $T_{0}$ codes for 13 amino acids (AA): Ala, Asn, Asp, Gln, Glu, Gly, Ile, Leu, Lys, Phe, Thr, Tyr and Val [Table 4(a)]. As $T_{0}$ has 22 codons, several codons of $T_{0}$ code for the same AA.

TABLE 4(a)

The subset $T_{0}$ (bold) codes for 13 amino acids in the universal genetic code: Ala, Asn, Asp, Gln, Glu, Gly, Ile, Leu, Lys, Phe, Thr, Tyr and Val

\begin{tabular}{|c|c|c|c|c|c|c|c|}
\hline Codon & Amino acid & Codon & Amino acid & Codon & Amino acid & Codon & Amino acid \\
\hline \multirow[t]{2}{*}{ TTT } & Phe, F & $\underline{\mathrm{TCT}}$ & Ser, S & $\underline{\underline{\mathrm{TAT}}}$ & Tyr, Y & $\underline{\underline{\mathrm{TGT}}}$ & Cys, C \\
\hline & $\begin{array}{l}\text { Phenylalanine } \\
\text { Phe, F }\end{array}$ & TCC & $\begin{array}{l}\text { Serine } \\
\text { Ser, S }\end{array}$ & TAC & $\begin{array}{l}\text { Tyrosine } \\
\text { Tyr, Y }\end{array}$ & TGC & $\begin{array}{l}\text { Cysteine } \\
\text { Cys, C }\end{array}$ \\
\hline TTC & Phenylalanine & $1 \mathrm{CL}$ & $\begin{array}{l}\text { Ser, s } \\
\text { Serine }\end{array}$ & $1 \mathrm{AC}$ & Tyrosine & 10 & Cysteine \\
\hline \multirow[t]{2}{*}{ TTA } & Leu, L & $\underline{\text { TCA }}$ & Ser, S & $\underline{\underline{\text { TAA }}}$ & Stop codon & $\underline{\underline{\text { TGA }}}$ & Stop codon \\
\hline & Leucine & TCG & $\begin{array}{l}\text { Serine } \\
\text { Ser S S }\end{array}$ & TAG & $\begin{array}{l}\text { ochre } \\
\text { Ston codon }\end{array}$ & TGG & opal \\
\hline$\underline{\text { TTG }}$ & Leucine & $1 C U$ & Serine & $1 \mathrm{AG}$ & $\begin{array}{l}\text { Stop codon } \\
\text { amber }\end{array}$ & $1 \mathrm{NU}$ & $\begin{array}{l}\text { IIp, w } \\
\text { Tryptophan }\end{array}$ \\
\hline \multirow[t]{2}{*}{$\underline{\underline{\mathrm{CTT}}}$} & Leu, L & $\underline{\underline{\mathrm{CCT}}}$ & Pro, $\mathrm{P}$ & $\underline{\underline{\mathrm{CAT}}}$ & His, $\mathrm{H}$ & $\underline{\mathrm{CGT}}$ & Arg, R \\
\hline & Leucine & & Proline & & Histidine & & Arginine \\
\hline \multirow[t]{2}{*}{ CTC } & Leu, L & $\mathrm{CCC}$ & Pro, $\mathrm{P}$ & CAC & His, $\mathrm{H}$ & CGC & Arg, R \\
\hline & Leucine & & Proline & & Histidine & & Arginine \\
\hline \multirow[t]{2}{*}{$\underline{\underline{\mathrm{CTA}}}$} & Leu, L & CCA & Pro, $\mathrm{P}$ & $\underline{\underline{\mathrm{CAA}}}$ & Gln, Q & $\underline{\mathrm{CGA}}$ & Arg, R \\
\hline & Leucine & & Proline & & Glutamine & & Arginine \\
\hline \multirow[t]{2}{*}{ CTG } & Leu, L & CCG & Pro, $\mathrm{P}$ & CAG & Gln, Q & CGG & Arg, R \\
\hline & Leucine & & Proline & & Glutamine & & Arginine \\
\hline \multirow[t]{2}{*}{ ATT } & Ile, I & ACT & Thr, T & AAT & Asn, $\mathrm{N}$ & AGT & Ser, S \\
\hline & Isoleucine & & Threonine & & Asparagine & & Serine \\
\hline \multirow{2}{*}{ ATC } & Ile, I & $\mathrm{ACC}$ & Thr, T & AAC & Asn, N & AGC & Ser, S \\
\hline & Isoleucine & & Threonine & & Asparagine & & Serine \\
\hline \multirow{2}{*}{ ATA } & Ile, I & ACA & Thr, T & AAA & Lys, K & $\underline{\underline{A G A}}$ & Arg, R \\
\hline & Isoleucine & & Threonine & & Lysine & & Arginine \\
\hline \multirow[t]{2}{*}{$\underline{\mathrm{ATG}}$} & Met, M & ACG & Thr, T & AAG & Lys, K & AGG & Arg, R \\
\hline & Methionine & & Threonine & & Lysine & & Arginine \\
\hline \multirow[t]{2}{*}{ GTT } & Val, V & $\underline{\mathrm{GCT}}$ & Ala, A & GAT & Asp, D & GGT & Gly, G \\
\hline & Valine & & Alanine & & Aspartic acid & & Glycine \\
\hline \multirow[t]{2}{*}{ GTC } & Val, V & GCC & Ala, A & GAC & Asp, D & GGC & Gly, G \\
\hline & Valine & & Alanine & & Aspartic acid & & Glycine \\
\hline \multirow[t]{2}{*}{ GTA } & Val, V & GCA & Ala, A & GAA & Glu, E & GGA & Gly, G \\
\hline & Valine & & Alanine & & Glutamic acid & & Glycine \\
\hline \multirow[t]{2}{*}{ GTG } & Val, V & GCG & Ala, A & GAG & Glu, E & $\underline{\underline{G G G}}$ & Gly, G \\
\hline & Valine & & Alanine & & Glutamic acid & & Glycine \\
\hline
\end{tabular}

Seven amino acids are not coded by $T_{0}$ : Arg, Cys, His, Met, Pro, Ser and Trp. The subset $T_{1}$ (underlined once) is associated with 11 amino acids: Ala, Arg, Cys, Ile, Leu, Lys, Met, Pro, Ser, Thr and Val. The subset $T_{2}$ (underlined twice) is associated with 11 amino acids: Ala, Arg, Cys, Gln, Gly, His, Leu, Pro, Ser, Trp and Tyr.

TABLE 4(b)

Number of trinucleotides of each subset $T_{0}, T_{1}$ and $T_{2}$ coding an amino acid

\begin{tabular}{cccccccccccccccccccccc}
\hline & Ala & Arg & Asn & Asp & Cys & Gln & Glu & Gly & His & Ile & Leu & Lys & Met & Phe & Pro & Ser & Thr & Trp & Tyr & Val \\
\hline$T_{0}$ & 1 & 0 & 2 & 2 & 0 & 1 & 2 & 2 & 0 & 2 & 2 & 1 & 0 & 2 & 0 & 0 & 1 & 0 & 1 & 3 \\
$T_{1}$ & 1 & 1 & 0 & 0 & 1 & 0 & 0 & 0 & 0 & 1 & 2 & 1 & 1 & 0 & 3 & 5 & 3 & 0 & 0 & 1 \\
$T_{2}$ & 2 & 5 & 0 & 0 & 1 & 1 & 0 & 2 & 2 & 0 & 2 & 0 & 0 & 0 & 1 & 1 & 0 & 1 & 1 & 0 \\
\hline
\end{tabular}


Six essential AA are coded by $T_{0}$ : Ile, Leu, Lys, Phe, Thr and Val (two essential AA are not coded by $T_{0}$ : Met and Trp). Almost all classes of AA are coded by $T_{0}$ : the simplest (Gly), aliphatic (Ala, Ile, Leu, Val), hydroxyl (Thr), acidic (Asp, Glu), amide (Asn, Gln), basic (Lys) and aromatic (Phe, Tyr) (two classes are not coded by $T_{0}$ : the sulfur-containing AA, Cys and Met, and the cyclic AA, Pro). There are some symmetrical features unexplained. The subsets $T_{1}$ and $T_{2}$ code a same number (11) of AA [Table 4(a)]. Table 4(b) gives the number of trinucleotides of each subset $T_{0}, T_{1}$ and $T_{2}$ coding an AA. Ser (resp. Arg) is coded by five trinucleotides of $T_{1}$ (resp. $T_{2}$ ) and by one trinucleotide of $T_{2}$ (resp. $T_{1}$ ). Val (resp. Thr) is coded by three trinucleotides of $T_{0}$ (resp. $T_{1}$ ) and by one trinucleotide of $T_{1}$ (resp. $T_{0}$ ). Otherwise, Asn, Asp, Glu and Phe are only coded by $T_{0}$, Met, by $T_{1}$ and, His and Trp, by $T_{2}$.

\subsection{CONSEQUENCES ON THE AMINO ACID FREQUENCIES IN PROTEINS}

Seven amino acids (AA) are not coded by the codon subset $T_{0}$ : Arg, Cys, His, Met, Pro, Ser and Trp [Table 4(a)]. Therefore, these seven AA should have the lowest frequencies in proteins. In order to verify this consequence of a code in protein genes, the frequencies of the $20 \mathrm{AA}$ are computed in 9510 prokaryotic proteins (3044028 AA) and 20673 eukaryotic proteins (7521044 AA). They are obtained from the protein data base SWISS-PROT (release 29 from June 1994). Then, these observed AA frequencies are compared with their expected AA frequencies (number of codons coding an AA divided by the total number of non-stop codons, i.e. 61). Table 5 shows that except for Met, the six other AA not coded by $T_{0}$, Arg, Cys, His, Pro, Ser and Trp, have the lowest observed/expected frequency ratios $(<0.8)$ in the proteins of both prokaryotes and eukaryotes. For Arg, a difference between the observed frequency and the frequency expected from the universal genetic code has already been mentioned (Jukes et al., 1975). Met is a particular case as the codon coding for Met is also the start codon for establishing the frame 0 (reading frame) in actual genes.

In summary, both in prokaryotes and eukaryotes, there is a strong correlation between the usage of the codons of $T_{0}$ in protein genes and the amino acid frequencies in proteins.

\subsection{CONSEQUENCES ON THE COMPLEMENTARY PAIRED DNA SEQUENCE}

As the set $X_{0}$ of trinucleotides is a circular code (property to retrieve automatically the frame 0 ) and self-complementary, the two paired frames 0 (reading frames) in the two DNA double helix may simultaneously code for amino acids without using a start codon (Fig. 4), in agreement with biological arguments (Zull \& Smith, 1990; Konecny et al., 1993;

TABLE 5

Observed/expected frequency ratios in the proteins of prokaryotes and eukaryotes

\begin{tabular}{|c|c|c|c|c|c|c|c|}
\hline \multirow{2}{*}{$\begin{array}{l}\text { Amino acid } \\
\text { (number of codons) }\end{array}$} & \multirow{2}{*}{$\begin{array}{c}\text { Expected } \\
\text { frequency } \\
(\% \text { rounded })\end{array}$} & \multicolumn{2}{|c|}{$\begin{array}{l}\text { Observed number } \\
\text { in proteins }\end{array}$} & \multicolumn{2}{|c|}{$\begin{array}{l}\text { Observed frequency }(\%) \\
\text { in proteins }\end{array}$} & \multicolumn{2}{|c|}{$\begin{array}{l}\text { Observed frequency/ } \\
\text { Expected frequency }\end{array}$} \\
\hline & & Prokaryotes & Eukaryotes & Prokaryotes & Eukaryotes & Prokaryotes & Eukaryotes \\
\hline Ala, A, Alanine $(4 / 61)$ & 6.56 & 287360 & 535229 & 9.44 & 7.12 & 1.44 & 1.08 \\
\hline Arg, R, Arginine (6/61) & 9.84 & 164498 & 377123 & 5.40 & 5.01 & 0.55 & 0.51 \\
\hline Asn, N, Asparagine $(2 / 61)$ & 3.28 & 127874 & 337816 & 4.20 & 4.49 & 1.28 & 1.37 \\
\hline Asp, D, Aspartic acid $(2 / 61)$ & 3.28 & 170363 & 392502 & 5.60 & 5.22 & 1.71 & 1.59 \\
\hline Gln, Q, Glutamine $(2 / 61)$ & 3.28 & 119579 & 312059 & 3.93 & 4.15 & 1.20 & 1.26 \\
\hline Glu, E, Glutamic acid $(2 / 61)$ & 3.28 & 190544 & 488770 & 6.26 & 6.50 & 1.91 & 1.98 \\
\hline Gly, G, Glycine $(4 / 61)$ & 6.56 & 234665 & 515987 & 7.71 & 6.86 & 1.18 & 1.05 \\
\hline His, H, Histidine $(2 / 61)$ & 3.28 & 63907 & 175381 & 2.10 & 2.33 & 0.64 & 0.71 \\
\hline Ile, I, Isoleucine $(3 / 61)$ & 4.92 & 180442 & 402872 & 5.93 & 5.36 & 1.20 & 1.09 \\
\hline Leu, L, Leucine $(6 / 61)$ & 9.84 & 288009 & 690767 & 9.46 & 9.18 & 0.96 & 0.93 \\
\hline Lys, K, Lysine $(2 / 61)$ & 3.28 & 158728 & 466467 & 5.21 & 6.20 & 1.59 & 1.89 \\
\hline Met, M, Methionine $(1 / 61)$ & 1.64 & 74134 & 173337 & 2.44 & 2.30 & 1.48 & 1.41 \\
\hline Pro, P, Proline $(4 / 61)$ & 6.56 & 132643 & 390457 & 4.36 & 5.19 & 0.66 & 0.79 \\
\hline Ser, S, Serine $(6 / 61)$ & 9.84 & 183680 & 568759 & 6.03 & 7.56 & 0.61 & 0.77 \\
\hline Thr, T, Threonine $(4 / 61)$ & 6.56 & 173058 & 424350 & 5.69 & 5.64 & 0.87 & 0.86 \\
\hline Trp, W, Tryptophan $(1 / 61)$ & 1.64 & 38564 & 92793 & 1.27 & 1.23 & 0.77 & 0.75 \\
\hline Tyr, Y, Tyrosine $(2 / 61)$ & 3.28 & 94076 & 238524 & 3.09 & 3.17 & 0.94 & 0.97 \\
\hline Val, V, Valine $(4 / 61)$ & 6.56 & 216702 & 475037 & 7.12 & 6.32 & 1.09 & 0.96 \\
\hline
\end{tabular}

Arg, Cys, His, Pro, Ser and Trp have the lowest observed/expected frequency ratios $(<0.8)$ in the proteins of both prokaryotes $(9510$ sequences, 3044028 amino acids) and eukaryotes (20673 sequences, 7521044 amino acids) as expected with the usage of the codons of $T_{0}$ in protein genes. 


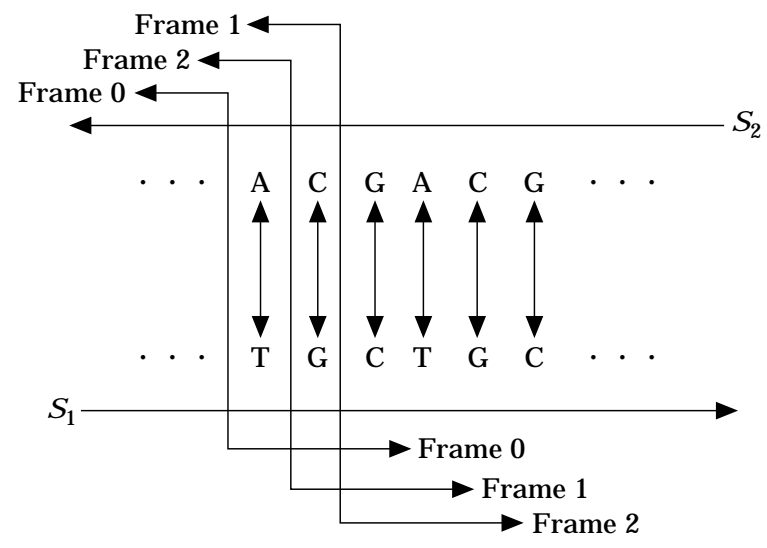

FIG. 4. The self-complementary circular code $X_{0}$ allows the two paired frames 0 (reading frames) simultaneously to code for amino acids without using a start codon.

Béland \& Allen, 1994; Konecny et al., 1995). Furthermore, as the sets $X_{1}$ and $X_{2}$ of trinucleotides are circular codes and complementary to each other and as a stop codon is never complementary to another stop codon, several frames among the six frames in the two DNA double helix may simultaneously code for amino acids without using a start codon, leading to an optimal information storage.

\section{Conclusion}

The identification in the protein genes of both prokaryotes and eukaryotes, of a circular code on the alphabet $\{A, C, G, T\}$ which automatically retrieves the frame after 13 nucleotides and which has exceptional properties of complementarity, circular permutation, rarity $\left(6 \times 10^{-8}\right)$, concatenation (high frequency of misplaced trinucleotides in the shifted frames, maximum length of the minimal window to automatically retrieve the frame and occurrence of the four types of nucleotides in the three trinucleotide sites) and coding amino acids by several codons, suggests that this code could have had a function in gene evolution and that the primitive alphabet could have been $\{A, C, G, T\}$ rather than $\{R, Y\}$.

We thank Prof. D. Perrin for his advice concerning the circular code. This work was supported by GIP GREG grant (Groupement d'Intérêt Public, Groupement de
Recherches et d'Etudes sur les Génomes), INSERM grant (Contrat de Recherche Externe No 930101) and $\mathrm{Mr}$ Jean-Marc Vassards (Director of the society RVH, Mulhouse).

\section{REFERENCES}

Arquès, D. G. \& Michel, C. J. (1987). A purine-pyrimidine motif verifying an identical presence in almost all gene taxonomic groups. J. theor. Biol. 128, 457-461.

Arquès, D. G. \& Michel, C. J. (1990a). Periodicities in coding and noncoding regions of the genes. J. theor. Biol. 143, 307-318.

ARQUÈs, D. G. \& MiChel, C. J. (1990b). A model of DNA sequence evolution, Part 1: Statistical features and classification of gene populations, Part 2: Simulation model, Part 3: Return of the model to the reality. Bull. Math. Biol. 52, 741-772.

Arouès, D. G. \& MicheL, C. J. (1993). Identification and simulation of new non-random statistical properties common to different eukaryotic gene subpopulations. Biochimie 75, 399-407.

ArquÈs, D. G. \& Michel, C. J. (1994). Analytical expression of the purine/pyrimidine autocorrelation function after and before random mutations. Math. Biosc. 123, 103-125.

Arquès, D. G., Lapayre, J.-C. \& Michel, C. J. (1995). Identification and simulation of shifted periodicities common to protein coding genes of eukaryotes, prokaryotes and viruses. $J$. theor. Biol. 172, 279-291.

BÉAL, M.-P. (1993). Codage Symbolique. Paris: Masson.

Béland, P. \& Allen, T. F. H. (1994). The origin and evolution of the genetic code. J. theor. Biol. 170, 359-365.

Berstel, J. \& Perrin, D. (1985). Theory of Codes. London: Academic Press.

Crick, F. H. C., Griffith, J. S. \& Orgel, L. E. (1957). Codes without commas. Proc. Natl. Acad. Sci. 43, 416-421.

Crick, F. H. C., Brenner, S., Klug, A. \& Pieczenik, G. (1976). A speculation on the origin of protein synthesis. Origins of Life 7, 389-397.

Dounce, A. L. (1952). Duplicating mechanism for peptide chain and nucleic acid synthesis. Enzymologia 15, 251-258.

Eigen, M. \& Schuster, P. (1978). The hypercycle. A principle of natural self-organization. Part C: The realistic hypercycle. Naturwissenschaften 65, 341-369.

Jukes, T. H. \& Bhushan, V. (1986). Silent nucleotide substitutions and $\mathrm{G}+\mathrm{C}$ content of some mitochondrial and bacterial genes. J. Mol. Evol. 24, 39-44.

Jukes, T. H., Holmquist, R. \& Moise, H. (1975). Amino acid composition of proteins: selection against the genetic code Science 189, 50-51.

Konecny, J., Eckert, M., Schöniger, M. \& Hofacker, G. L. (1993). Neutral adaptation of the genetic code to double-strand coding. J. Mol. Evol. 36, 407-416.

Konecny, J., Schöniger, M. \& Hofacker, G. L. (1995). Complementary coding conforms to the primeval comma-less code J. theor. Biol. 173, 263-270.

Nirenberg, M. W. \& Matthaei, J. H. (1961). The dependance of cell-free protein synthesis in E. Coli upon naturally occurring or synthetic polyribonucleotides. Proc. Natl. Acad. Sci. 47, $1588-1602$

WAtson, J. D. \& CRICK, F. H. C. (1953). A structure for deoxyribose nucleic acid. Nature 171, 737-738.

ZulL, J. E. \& SMith, S. K. (1990). Is genetic code redundancy related to retention of structural information in both DNA strands? Trends Biochem. Sci. 15, 257-261. 